\title{
MODELOS MENTAIS DOS ALUNOS SOBRE A PILHA DE DANIELL: investigação com o aplicativo stop motion ${ }^{1}$
}

\author{
Angélica Mattiolli Rodrigues \\ Universidade Estadual Paulista "Júlio de Mesquita Filho" \\ angelicamattiolli@gmail.com \\ Gustavo Bizarria Gibin \\ Universidade Estadual Paulista "Júlio de Mesquita Filho" \\ gustavo.gibin@unesp.br
}

\begin{abstract}
RESUMO
Neste trabalho foram realizadas investigações sobre os modelos mentais dos alunos sobre as transformações eletroquímicas na pilha de Daniell. Para isso, utilizou-se como referencial teórico a teoria de modelos mentais de Johnson-Laird, e foi aplicado um minicurso de 9 horas para 23 alunos do Ensino Médio da Escola Estadual Professor Francisco Balduíno de Souza em Quatá - SP, o qual envolveu a elaboração de animações por meio do aplicativo Stop Motion, realização de experimentos e relatórios pelos alunos. Tais atividades desenvolvidas, além do questionário aplicado, forneceram dados sobre as modificações nos modelos mentais dos alunos sobre a geração de corrente elétrica e aspectos relacionados às reações químicas representadas em nível atômico-molecular. A metodologia de pesquisa envolveu uma análise qualitativa dos dados, pois o nível de abstração dos modelos mentais demanda tal tratamento, ao se investigar o processo de compreensão dos sistemas eletroquímicos com auxílio de materiais imagéticos associados às animações. Como resultado, observou-se que muitos dos alunos possuem uma noção superficial sobre o funcionamento submicroscópico ou atômico-molecular dos sistemas eletroquímicos, e falta de experiência na elaboração de relatórios de experimentação. Os vídeos desenvolvidos em Stop Motion demonstraram a dificuldade dos envolvidos em compreender a estequiometria das reações, o processo de transferência de elétrons e aspectos inerentes às etapas intermediárias das reações químicas, pontos falhos que podem ser detectados por meio da técnica empregada e corrigidos pelo professor ao longo do processo de ensino-aprendizagem.
\end{abstract}

Palavras-chave: Ensino de Química. Eletroquímica. Smartphone.

${ }^{1}$ Este artigo é a versão expandida de uma comunicação oral apresentada no VII Simpósio de Educação Inclusiva e Adaptações/ V Simpósio Internacional de Educação a Distância. São Paulo, UNESP, 2019. 


\title{
MENTAL MODELS OF STUDENTS ABOUT DANIELL'S CELL: research with the stop motion application
}

\begin{abstract}
In this work was carried out an investigation about the mental models of the students on the electrochemical transformations at cell of Daniell. The theoretical framework used was the mental models theory by Johnson-Laird. A 9-hour mini-course was applied to 23 students of the High School of the State School Professor Francisco Balduino de Souza in city of Quatá - SP, which involved the elaboration of animations through the Stop Motion application, conducting experiments and reports by the students. In addition to the applied questionnaire, these activities provided data about the modifications in students' mental models regarding the generation of electric current and aspects about the submicroscopic reactions involved. The research methodology involved a qualitative analysis of the data, since the level of abstraction of the mental models demands such treatment, when investigating the process of understanding the electrochemical systems with the aid of imagery materials associated with the animations. As a result, it has been observed that many of the students have a superficial notion about the submicroscopic functioning of electrochemical systems, and lack of experience in producing experimental reports. The videos developed in Stop Motion demonstrated the difficulty of those involved in understanding the stoichiometry of reactions, the electron transfer process and aspects inherent to the intermediary stages of the chemical reactions, faulty points that can be detected by the technique employed, and corrected by the teaching-learning process.
\end{abstract}

Keywords: Chemistry Teaching. Electrochemistry. Smartphone.

\section{MODELOS MENTALES DE ESTUDIANTES SOBRE LA PILA DE DANIELL: investigación con la aplicación de stop motion}

\section{RESUMEN}

En este trabajo, se llevaron a cabo investigaciones sobre los modelos mentales de los estudiantes sobre las transformaciones electroquímicas en la célula de Daniell. Para eso, se utilizó la teoría de los modelos mentales de Johnson-Laird como marco teórico, y se aplicó un mini curso de 9 horas a 23 estudiantes de secundaria, en la Escuela Estatal Profesor Francisco Balduíno de Souza en Quatá - SP, fue realizada la elaboración de animaciones mediante la aplicación Stop Motion, realización de experimentos e de informes por los alumnos. Dichas actividades desarrolladas, 
además del cuestionario aplicado, proporcionaron datos sobre los cambios en los modelos mentales de los estudiantes sobre la generación de corriente eléctrica y aspectos relacionados con las reacciones químicas representadas a nivel atómicomolecular. La metodología de investigación implicó un análisis cualitativo de los datos, ya que el nivel de abstracción de los modelos mentales exige dicho tratamiento, al investigar el proceso de comprensión de los sistemas electroquímicos con la ayuda de materiales de imágenes asociados con las animaciones. Como resultado, se observó que muchos de los estudiantes tienen una noción superficial sobre el funcionamiento submicroscópico o atómico-molecular de los sistemas electroquímicos, y una falta de experiencia en la elaboración de informes de experimentación. Los videos de Stop Motion desarrollados, demostraron la dificultad de los involucrados en comprender la estequiometria de las reacciones, el proceso de transferencia de electrones y los aspectos inherentes a las etapas de intermedios de las reacciones químicas, puntos defectuosos, que pueden detectarse, utilizando la técnica empleada y corregidos por el profesor, a lo largo del prooceso de enseñanza-aprendizaje.

Palabras clave: Enseñanza de la química. Electroquímica. Smartphone.

\section{INTRODUÇÃO}

$\mathrm{Na}$ realidade do sistema de ensino vigente, os alunos não agem de modo ativo no processo de ensino e aprendizagem, mas sim atuam armazenando passivamente as informações que lhes são apresentadas, sem ter uma reflexão significativa sobre tais conhecimentos (MOREIRA; GRECA; PALMERO, 2002). Nesse sentido, novas abordagens de ensino estão sendo pesquisadas a fim de resolver ou atenuar este problema.

De certo modo, o ensino tradicional desvinculado do cotidiano dos alunos, sem trazer questionamentos ou oportunidades de participação em aula (SILVA, 2013; ROCHA et al., 2017), além do incentivo à memorização e ao armazenamento desconexo de informações, podem ser fatores que tornam a Química desinteressante para parte dos alunos. As reconstruções mentais dos fenômenos presentes no mundo externo são essenciais para que a aprendizagem seja autêntica, uma vez que não ocorre por meio da simples memorização das informações conceituais e expressões simbólicas aplicadas aos fenômenos científicos, conforme Moreira, Greca e Palmero (2002).

Ao considerar os aspectos eletroquímicos, difíceis de serem compreendidos, já que envolvem o nível atômico e molecular de representação da matéria, o que confere abstração e complexidade aos conceitos envolvidos, é possível observar que as maiores dificuldades dos alunos estão especificamente relacionadas a pilha de 
Daniell, conforme os dados levantados pela pesquisa de Caramel e Pacca (2011), se tratam da explicação das reações em nível submicroscópico, onde os alunos confundem os termos "cátions”, "ânions", "íons”, "oxidação”, utilizando-os em sentidos diferentes em relação ao que a ciência aceita como adequado. Além disso, o processo de oxido-redução, muitas vezes, é incorretamente interpretado pelos alunos como um intercâmbio de oxigênio, e não de elétrons (BUESO, FURIÓ e MANS, 1998; ROCHA et al., 2017; FREIRE, SILVA JÚNIOR e SILVA, 2012). Também há casos em que os alunos consideram a ponte salina uma "doadora" de elétrons que completa o circuito da pilha (ROCHA et al., 2017), ao invés de uma região com cátions e ânions que proporciona o equilíbrio eletrostático.

Segundo Russel et al. (1997), as dificuldades em "enxergar" o mundo abstrato dos íons, átomos e moléculas, que está envolvido com as equações e símbolos químicos e com a compreensão das reações subatômicas, podem ser contornadas pela utilização de animações referentes a estas espécies químicas submicrocópicas. As animações colaboram para a construção de modelos mentais mais precisos, sendo que modelo mental é um tipo de representação interna, correspondente a compreensão de teorias ou entendimento de estruturas da realidade externa.

A melhora na aprendizagem através de animações ocorre, conforme Johnstone (1993), porque o aluno pode ter uma maior facilidade em correlacionar os níveis representacionais macroscópico (visível e palpável), submicroscópico (atômico e molecular), e simbólico (utilizado por livros - simbologia química).

Avanços cognitivos notáveis podem ser alcançados com a utilização de animações/vídeos que expressam o dinamismo das espécies subatômicas, assim como a natureza abstrata da matéria (RUSSEL, et al. 1997). A "manipulação" do nível submicroscópico pode ser conseguida por parte do aluno, por meio de figuras representativas dessas espécies, levando a uma maior compreensão do caráter abstrato da matéria, e consequentemente a uma melhor compreensão da simbologia química (como equações químicas) e das evidências de reações visíveis em nível macroscópico.

\section{OBJETIVO}

Investigar as representações que os alunos apresentam em relação a compreensão do funcionamento da pilha de Daniell, por meio da análise das atividades desenvolvidas (respostas a um questionário inicial, relatório de experimentos e desempenho na elaboração de animações relativas à dinâmica reacional das moléculas em nível submicroscópico). 


\section{FUNDAMENTAÇÃO TEÓRICA}

Quando procura-se compreender uma teoria, fenômeno ou obter entendimento relativo a algo, desenvolvemos internamente uma estrutura análoga ao que procuramos compreender. Três tipos de representações internas (versão consciente, reflexiva e dinâmica da teoria, conceito ou objeto a ser interpretado) podem ser citadas segundo a teoria proposta por Johnson-Laird (1983): representações proposicionais, modelos mentais e imagens.

Representações proposicionais ou proposições são uma sequência de símbolos, que conjuntamente passam a expressar significado. Dessa forma, as proposições se relacionam com a linguagem natural, ou seja, são formas de "entrada", e agem como auxiliares para construção dos modelos mentais (JOHNSON-LAIRD, 1983).

Já os modelos mentais são representações internas correspondentes à compreensão de teorias e conceitos científicos, assim como pode ser uma representação de algum objeto que não esteja realmente presente, de forma que age como um análogo estrutural do mundo exterior, empírico e real, e reflete a realidade física correspondente. Ou também age como um análogo estrutural do mundo imaginário, e reflete a realidade abstrata correspondente às ideias, conceitos e ao imperceptível mundo subatômico (MOREIRA; GRECO; PALMERO, 2002).

As imagens, assim como os modelos mentais, correspondem a representações internas muito específicas, e que possibilitam ter a noção, não precisa, do modelo mental em constante desenvolvimento (JOHNSON-LAIRD, 1983). A partir disso, torna-se possível realizar uma análise dos modelos mentais por meio de imagens exteriorizadas pelos alunos, onde podemos investigar a forma como tais modelos são construídos.

Segundo Norman (1983), os modelos mentais são carregados de dinamismo e de instabilidade e não são estruturados de maneira sólida, já que são evidentes as suas simplificações e incompletudes, que constantemente se alteram, pois ao longo do tempo, conceitos e ideias semelhantes passam a ser confundidos, e alguns detalhes são esquecidos.

É importante corrigir os erros conceituais presentes nos modelos mentais dos alunos, tornando necessário conhecê-los e analisar suas modificações ao longo do tempo, para que tais modelos se tornem mais precisos e mais próximos da realidade. Conforme Gibin (2009), para que o professor passe a ter conhecimento dos modelos mentais dos alunos, estes últimos devem ter uma participação ativa, de modo que suas ideias e opiniões sobre o fenômeno químico sejam levadas em conta durante o processo de ensino-aprendizagem. 


\section{METODOLOGIA}

Um minicurso de 9 horas sobre eletroquímica foi oferecido aos alunos do Ensino Médio da Escola Estadual Professor Francisco Balduíno de Souza, da cidade de Quatá - SP, com a participação de 23 alunos de diferentes anos do Ensino Médio. Foram realizadas discussões conceituais, atividades experimentais e o desenvolvimento de animações sobre as reações químicas da pilha de Daniell em nível submicrocópico.

Os alunos também responderam um questionário inicial, para levantar seus conhecimentos prévios sobre eletroquímica: corrente elétrica, distinção entre cátodo e ânodo, oxidação e redução de metais, assim como diferenças entre eletrólise e pilhas. O quadro 1 apresenta as atividades realizadas ao longo do minicurso.

Quadro 1 - Etapas realizadas ao longo do minicurso.

\begin{tabular}{|c|c|}
\hline Etapas & Características de cada etapa \\
\hline $\begin{array}{l}\text { Aprendendo a produzir } \\
\text { vídeos em Stop Motion }\end{array}$ & $\begin{array}{l}\text { Após uma introdução sobre o aplicativo e seu funcionamento, } \\
\text { os alunos elaboraram animações por meio da movimentação de } \\
\text { objetos inanimados ou desenhos feitos por eles mesmos, a fim } \\
\text { de se familiarizar com a técnica. }\end{array}$ \\
\hline $\begin{array}{l}\text { Discussão teórica sobre } \\
\text { a pilha de Daniell }\end{array}$ & $\begin{array}{l}\text { Comentou-se sobre a descoberta das pilhas, e posteriormente } \\
\text { discutiu-se sobre as reações de oxirredução, a distinção dos } \\
\text { polos (cátodo e ânodo), as diferentes tendências de reação dos } \\
\text { metais, a diferença de potencial e corrente elétrica. }\end{array}$ \\
\hline $\begin{array}{l}\text { Realização do } \\
\text { experimento da pilha de } \\
\text { Daniell }\end{array}$ & $\begin{array}{l}\text { Os alunos receberam um roteiro experimental e se organizaram } \\
\text { em grupos de } 3 \text { a } 5 \text { membros, e cada grupo recebeu uma cuba } \\
\text { eletroquímica, eletrodos de cobre e zinco, soluções de } \mathrm{CuSO}_{4} \mathrm{e} \\
\mathrm{ZnSO}_{4} \text {. Posteriormente, foi solicitado que os alunos realizassem } \\
\text { a elaboração de um relatório sobre a prática experimental. }\end{array}$ \\
\hline $\begin{array}{l}\text { Produção de Animações } \\
\text { em Stop Motion. }\end{array}$ & $\begin{array}{l}\text { Cada grupo recebeu uma suficiente quantidade de figuras } \\
\text { impressas das espécies químicas e do sistema, necessárias nas } \\
\text { representações, além de uma placa branca de PVC por grupo, } \\
\text { que serviu de plano de fundo para a produção da animação, } \\
\text { para representar as reações subatômicas presentes na pilha de } \\
\text { Daniell. }\end{array}$ \\
\hline $\begin{array}{l}\text { Apresentação da } \\
\text { animação feita pela } \\
\text { pesquisadora. }\end{array}$ & $\begin{array}{l}\text { A animação feita pela pesquisadora foi mostrada aos alunos e } \\
\text { explicada, para discutir as dúvidas e proporcionar uma melhor } \\
\text { compreensão do tema. }\end{array}$ \\
\hline
\end{tabular}

Fonte: Elaborado pelos autores.

O questionário inicial aplicado, que possuía seis questões relativas à eletroquímica, permitiu obter dados sobre o conhecimento prévio dos alunos. $\mathrm{E}$ sobre tais dados, efetuou-se uma categorização em Compreensão Total (respostas 
totalmente corretas para 80 a $100 \%$ das questões), Compreensão Mediana (êxito total ou parcial de $50 \%$ a $80 \%$ das questões) e Compreensão Baixa (acertos parciais para $0 \%$ a $50 \%$ das questões, envolvendo respostas inexistentes ou inconclusivas).

Embora tenha-se utilizado uma categorização quantitativa dos dados, por meio da obtenção do percentual de alunos que se enquadraram em determinada categoria de compreensão dos conceitos, as respostas ao questionário foram avaliadas de forma qualitativa, ou seja, não exata e descritiva, já que um modelo mental é algo inexato, dinâmico e incompleto, conforme Norman (1983). Dessa forma, qualquer tipo de expressão foi considerado como ponto de partida para analisar o modelo mental do aluno, desde que tais expressões estivessem devidamente representadas na forma de desenhos ou escrita.

Quanto ao relatório, este foi avaliado pela sua estrutura (Introdução, Objetivos, Materiais e Métodos, Resultados e Discussão e Conclusão) e pelo nível de envolvimento do aluno tanto pela prática quanto pela teoria envolvida. Por isso, os alunos nessa etapa foram classificados como possuindo "Alto Discernimento TeóricoEmpírico", para quando houve envolvimento com a parte prática e demonstração de explicações para as reações eletroquímicas observadas); "Médio Discernimento Teórico-Empírico", para alto envolvimento com as etapas experimentais e ausência de explicações teóricas - ou envolvimento com a parte conceitual do relatório, sem interpretar satisfatoriamente as reações empíricas observadas); e "Baixo Discernimento Teórico-Empírico" para relatórios onde o aluno não demonstrou estar atento e envolvido com os procedimentos experimentais, nem ter tentado explicar teoricamente as reações eletroquímicas).

Ao se analisar as animações, os seguintes elementos (tokens) foram levados em consideração: fluxo de elétrons, reações de oxirredução, estequiometria, oxidação dos átomos de zinco a $\mathrm{Zn}^{2+}$, deposição de cobre no cátodo e acendimento da lâmpada.

A análise das animações teve natureza essencialmente qualitativa, pois segundo Flick (2009) e Günther (2006), quando uma pesquisa se fundamenta na análise de dados de natureza visual ou textual, e se efetua uma interpretação descritiva e reflexiva, sem o isolamento de variáveis, se trata de uma metodologia qualitativa, pois requer uma construção subjetiva de teorias e examina-se interações e contextos de modo mais abrangente em comparação com o método quantitativo. Este último, no entanto, segundo Günther (2006), fundamenta-se na quantificação de dados sem levar em conta aspectos subjetivos. Nesse sentido, a análise das animações tem natureza descritiva e qualitativa, pois contou com a observação indireta de evidências dos modelos mentais dos alunos, na forma de conteúdo visual (animações desenvolvidas por meio do aplicativo Stop Motion). 


\section{RESULTADOS E DISCUSSÃO}

\subsection{Conhecimentos prévios associados a eletroquímica}

Por meio da análise das respostas ao questionário inicial, pôde-se constatar que nenhum dos alunos se enquadrou na categoria "Compreensão Total", ou seja, os estudantes investigados não possuíam concepções corretas sobre todas as seis questões abordadas. Cerca de $55 \%$ dos alunos se enquadraram em "Compreensão Mediana", já que responderam de forma total ou parcialmente correta de $50 \%$ a $80 \%$ das questões. A maior porcentagem encontrada (65\%) foi de alunos categorizados como possuindo "Compreensão Baixa", o que significa êxito parcial em 3 ou menos questões, ou erro absoluto em todas elas. Portanto, houve muita dificuldade de compreensão inicial sobre esse assunto pela grande parte dos alunos.

A maioria dos alunos apresentou uma maior dificuldade ou um modelo inadequado sobre o que seria um elétron e como este se movimentaria no sistema eletroquímico. Foram observadas muitas confusões e conceitos errados vinculados à distinção entre pilhas e eletrólise, tornando seus modelos repletos de dúvidas e conceitos superficiais. Na maioria das vezes não houve resposta, pois o aluno desconhecia o funcionamento do sistema (respostas nulas foram obtidas na maioria questões).

\subsection{Relatório sobre o experimento da pilha de Daniell}

A maior parte dos relatórios (70\%) se enquadrou em "Médio Discernimento Teórico-Empírico", o que significa que houve um destaque nos "Procedimentos Experimentais" em detrimento das explicações científicas para os fenômenos. As explicações conceituais sobre corrosão e reações de oxirredução estavam pela metade, ou presentes em outra categoria do relatório, como nas "Conclusões" ou na "Introdução". Isso sugere que os alunos podem não ter familiaridade com a realização de atividades experimentais, nas quais se exige um relatório de estudo.

Entretanto, cerca de $13 \%$ dos relatórios conseguiram se enquadrar na categoria "Alto Discernimento Teórico-Empírico", o que foi considerado como um bom resultado, demonstrando que os alunos se atentaram nas orientações e explicações e souberam realizar pesquisas e observações, categorizando devidamente as informações, dados e discussões requeridas. Um total de 4 alunos $(17,4 \%)$ se enquadrou em "Baixo Discernimento Teórico - Empírico", devido a carência de dados experimentais, informações pesquisadas e discussões ou justificativas para o fenômeno observado, além da não categorização em Tópicos, como foi requerido.

No entanto, também é preciso considerar que, sendo muitas vezes rara a realização de atividades práticas e de relatórios experimentais em muitas das escolas 
da rede pública de ensino (SILVA et al., 2011), muitas das informações não estavam categorizadas como deveriam, assim como são poucos os alunos que conseguiram descrever detalhadamente toda a metodologia do experimento e entender o fenômeno ocorrido justificando-o em termos científicos no tópico "Resultados e Discussão", o qual estava ausente em muitos relatórios.

\subsection{Observação e análise das animações sobre a pilha de Daniell}

As representações relativas às reações em nível submicroscópico permitiram localizar as principais dúvidas dos alunos sobre o sistema eletroquímico, as quais estão associadas principalmente à estequiometria das reações de oxirredução, e à coerência da movimentação das espécies subatômicas (erros cinemáticos), o que é compreensível devido ao grau de abstração dos conceitos.

O grupo 1 desenvolveu a animação apresentada de forma sintética na figura 1 , com um modelo que mais se aproximou do funcionamento real do sistema. Houve a representação da oxidação de átomos de zinco, liberando íons $\mathrm{Zn}^{2+}{ }_{(\text {aq })}$ e elétrons, assinalada nos quadros 2 e 3 respectivamente da figura 1, que percorrem o sistema e causam redução dos íons $\mathrm{Cu}^{2+}{ }_{(\text {aq }) \text {. }}$

Figura 1 - Representação feita pelo Grupo 1.

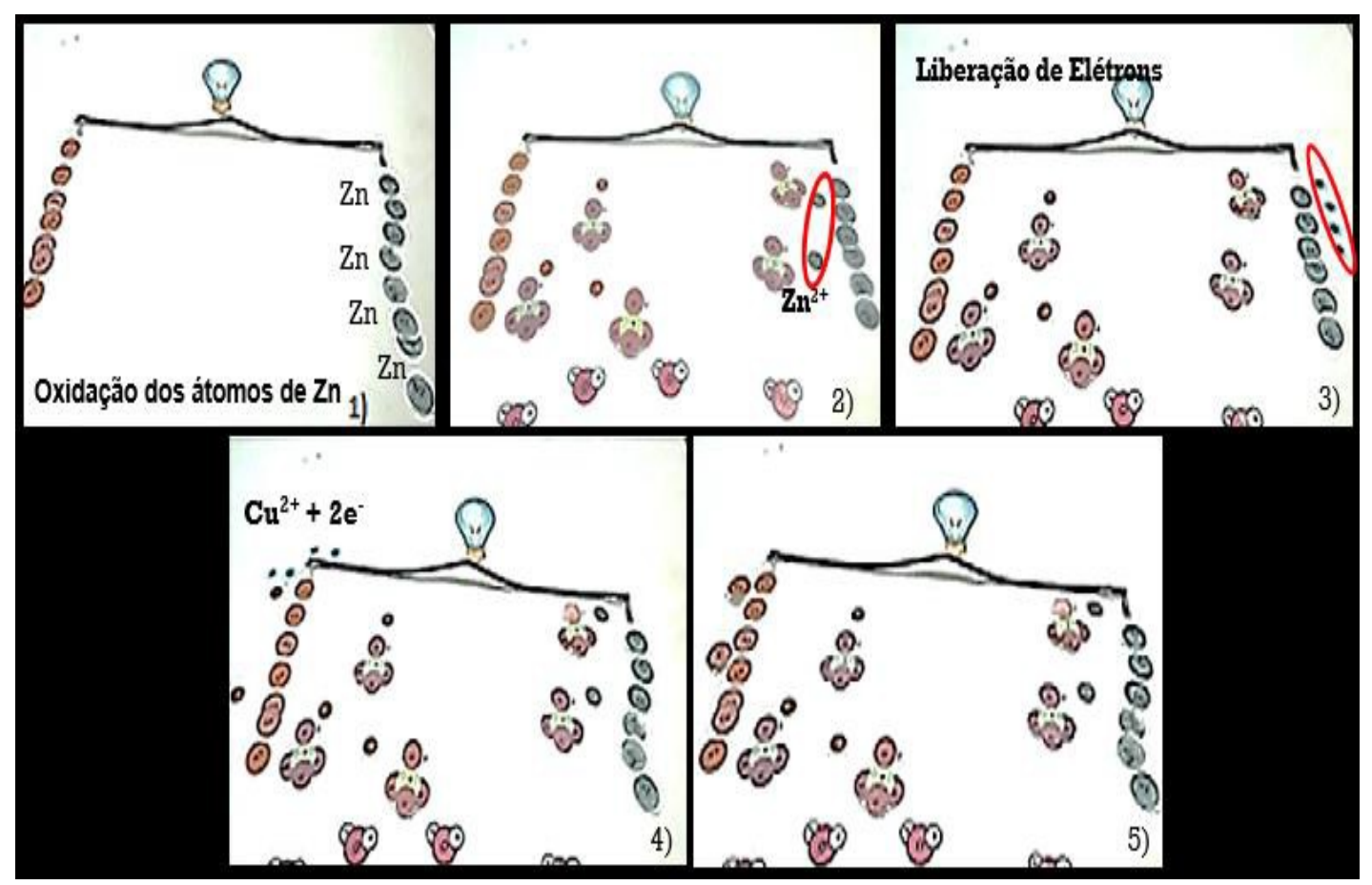

Fonte: Elaborado pelos autores. 
Quadro 2 - Resultados obtidos pela análise das animações

representacionais.

\begin{tabular}{|c|c|c|c|c|c|c|}
\hline Grupo & $\begin{array}{l}\text { Fluxo de } \\
\text { elétrons }\end{array}$ & $\begin{array}{l}\text { Representação } \\
\text { dos processos } \\
\text { de oxirredução }\end{array}$ & $\begin{array}{l}\text { Compreensão } \\
\text { sobre a massa } \\
\text { dos eletrodos }\end{array}$ & $\begin{array}{l}\text { Acendimento } \\
\text { da lâmpada }\end{array}$ & Estequiometria & $\begin{array}{l}\text { Dinâmica } \\
\text { das espécies } \\
\text { subatômicas }\end{array}$ \\
\hline 1 & $\begin{array}{l}\text { Correto. Vai } \\
\text { do ânodo } \\
\text { (eletrodo } \\
\text { de zinco) } \\
\text { ao cátodo } \\
\text { (eletrodo de } \\
\text { cobre). }\end{array}$ & $\begin{array}{l}\text { Correto. O } \\
\text { Zinco metálico } \\
\text { é oxidado a } \\
\mathrm{Zn}_{(\mathrm{aq})}^{2+} \text {, gerando } \\
2 \text { elétrons que } \\
\text { fluem na forma } \\
\text { de corrente e } \\
\text { reduzem os } \\
\text { íons } \\
\mathrm{Cu}^{2+}\end{array}$ & $\begin{array}{l}\text { Correto. Os } \\
{\text { íons } \mathrm{Cu}^{2+}}^{(\mathrm{aq})} \\
\text { reduziram a } \\
\text { cobre metálico. } \\
\text { Os átomos } \\
\text { de Zn eram } \\
\text { oxidados e } \\
\text { liberados } \\
\text { na solução } \\
\text { aquosa. }\end{array}$ & $\begin{array}{l}\text { Correto. } \\
\text { Os elétrons } \\
\text { fluem do } \\
\text { ânodo ao } \\
\text { cátodo, } \\
\text { ercorre- se o } \\
\text { fio condutor, } \\
\text { acendendo } \\
\text { uma lâmpada. }\end{array}$ & $\begin{array}{l}\text { Correto. Para } \\
\text { cada zinco } \\
\text { oxidado surgiam } \\
2 \text { elétrons, que } \\
\text { reduziram um } \\
{\text { íon } \mathrm{Cu}_{(\text {aq) }}^{2+} \text { a }}_{\text {cobre. }}\end{array}$ & $\begin{array}{l}\text { Parcialmente } \\
\text { correto. } \\
\text { Os íons } \\
\mathrm{Zn}^{2+} \\
\text { surgiram } \\
\text { de modo } \\
\text { espontâneo. }\end{array}$ \\
\hline 2 & $\begin{array}{l}\text { Correto. } \\
\text { Surgem } \\
\text { elétrons no } \\
\text { ânodo, que } \\
\text { percorrem } \\
\text { o fio em } \\
\text { direção ao } \\
\text { cátodo. }\end{array}$ & $\begin{array}{l}\text { Incorreto. } \\
\text { Os íons } \\
\text { surgiam de } \\
\text { forma aleatória } \\
\text { e ao acaso no } \\
\text { sistema, sem } \\
\text { coerência. }\end{array}$ & $\begin{array}{l}\text { Parcialmente } \\
\text { correto. O } \\
\text { eletrodo de } \\
\text { Zn não perdia } \\
\text { átomos; mas } \\
\text { o eletrodo de } \\
\text { cobre ganhava } \\
\text { átomos } \\
\text { depositados. }\end{array}$ & $\begin{array}{l}\text { Incorreto. } \\
\text { Não houve } \\
\text { representação } \\
\text { do } \\
\text { acendimento } \\
\text { da lâmpada, } \\
\text { com o fluxo de } \\
\text { elétrons. }\end{array}$ & $\begin{array}{l}\text { Incorreto. Os } \\
\text { íons e elétrons } \\
\text { não seguiam a } \\
\text { estequiometria } \\
\text { das reações. }\end{array}$ & $\begin{array}{l}\text { Incorreto. } \\
\text { As espécies } \\
\text { surgiam e } \\
\text { desapareciam } \\
\text { aleatoriamente } \\
\text { no sistema. }\end{array}$ \\
\hline 3 & $\begin{array}{l}\text { Parcialmen-te } \\
\text { correto. Os } \\
\text { elétrons não } \\
\text { percorrem o } \\
\text { fio condutor } \\
\text { de forma } \\
\text { retilínea }\end{array}$ & $\begin{array}{l}\text { Parcialmente } \\
\text { correto. Não há } \\
\text { oxidação do Zn, } \\
\text { embora ocorra } \\
\text { a redução dos } \\
\text { íons } \\
\mathrm{Cu}^{2+} \text { (aq). }\end{array}$ & $\begin{array}{l}\text { Correto. } \\
\text { Conforme } \\
\text { o fluxo de } \\
\text { elétrons, há } \\
\text { uma perda } \\
\text { de zinco, e } \\
\text { um ganho de } \\
\text { átomos de } \\
\text { cobre pelo } \\
\text { cátodo. }\end{array}$ & $\begin{array}{l}\text { Correto. } \\
\text { Durante a } \\
\text { movimentação } \\
\text { dos elétrons } \\
\text { no fio, a } \\
\text { lâmpada } \\
\text { permanece } \\
\text { acesa. }\end{array}$ & $\begin{array}{l}\text { Parcialmente } \\
\text { correto. A } \\
\text { estequiometria } \\
\text { é perdida } \\
\text { ao longo da } \\
\text { representação. }\end{array}$ & $\begin{array}{l}\text { Parcialmente } \\
\text { correto. } \\
\text { Problemas } \\
\text { na disposição } \\
\text { espacial de } \\
\text { espécies. }\end{array}$ \\
\hline $4,5,6$ & $\begin{array}{l}\text { Parcialmente } \\
\text { correto. } \\
\text { Em alguns } \\
\text { momentos, } \\
\text { os elétrons } \\
\text { surgem } \\
\text { de modo } \\
\text { incoerente. }\end{array}$ & $\begin{array}{l}\text { Parcialmente } \\
\text { correto nos } \\
\text { grupos } 5 \text { e 6: } \\
\text { sem oxidação } \\
\text { do Zn, mas } \\
\text { há redução } \\
{\text { de } \mathrm{Cu}^{2+}}^{\text {(aq). }} \\
\text { Incorreto no } \\
\text { grupo 4: sem } \\
\text { oxirredução. }\end{array}$ & $\begin{array}{l}\text { Correto. } \\
\text { Os grupos } \\
\text { representaram } \\
\text { a perda de } \\
\text { átomos } \mathrm{Zn} \\
\text { e o ganho } \\
\text { de átomos } \\
\text { de cobre no } \\
\text { cátodo. }\end{array}$ & $\begin{array}{l}\text { Correto. } \\
\text { Há } \\
\text { acendimento } \\
\text { da lâmpada } \\
\text { ao longo da } \\
\text { movimentação } \\
\text { de elétron pelo } \\
\text { fio condutor. }\end{array}$ & $\begin{array}{l}\text { Parcialmente } \\
\text { correto. O } \\
\text { número de } \\
\text { elétrons não } \\
\text { depende do } \\
\text { número de } \\
\mathrm{Zn}^{2+} \\
\text { (aq). }\end{array}$ & $\begin{array}{l}\text { Incorreto. Há } \\
\text { movimento } \\
\text { incoerente } \\
\text { de íons e } \\
\text { elétrons } \\
\text { em vários } \\
\text { momentos. }\end{array}$ \\
\hline
\end{tabular}

Fonte: Elaborado pelos autores.

O quadro 2 descreve os erros, acertos e representações parcialmente corretas. O grupo 1 obteve o melhor resultado, embora tenha cometido erros de natureza cinemática, como o surgimento aleatório e incoerente de espécies químicas em determinado lugar do sistema. Tais erros na disposição espacial das moléculas e íns foram cometidos por todos os grupos, devido ao complicado nível de abstração do sistema. 
A estequiometria das reações, na maioria das vezes, foi obedecida apenas inicialmente, o que foi avaliado como parcialmente correto, pois posteriormente houve incoerências em termos estequiométricos das reações de oxirredução, e na coerência na movimentação das espécies químicas. Os grupos representaram de modo satisfatório o acendimento da lâmpada (menos o grupo 2), e todos compreenderam, mesmo que de modo parcial em alguns casos, a oxidação do ânodo e o recobrimento metálico no cátodo. Os processos de oxirredução foram totais ou parcialmente representados corretamente, com exceção do grupo 2 , que cometeu o maior número de erros, conforme a figura 2.

Figura 2 - Representação feita pelo Grupo 2.

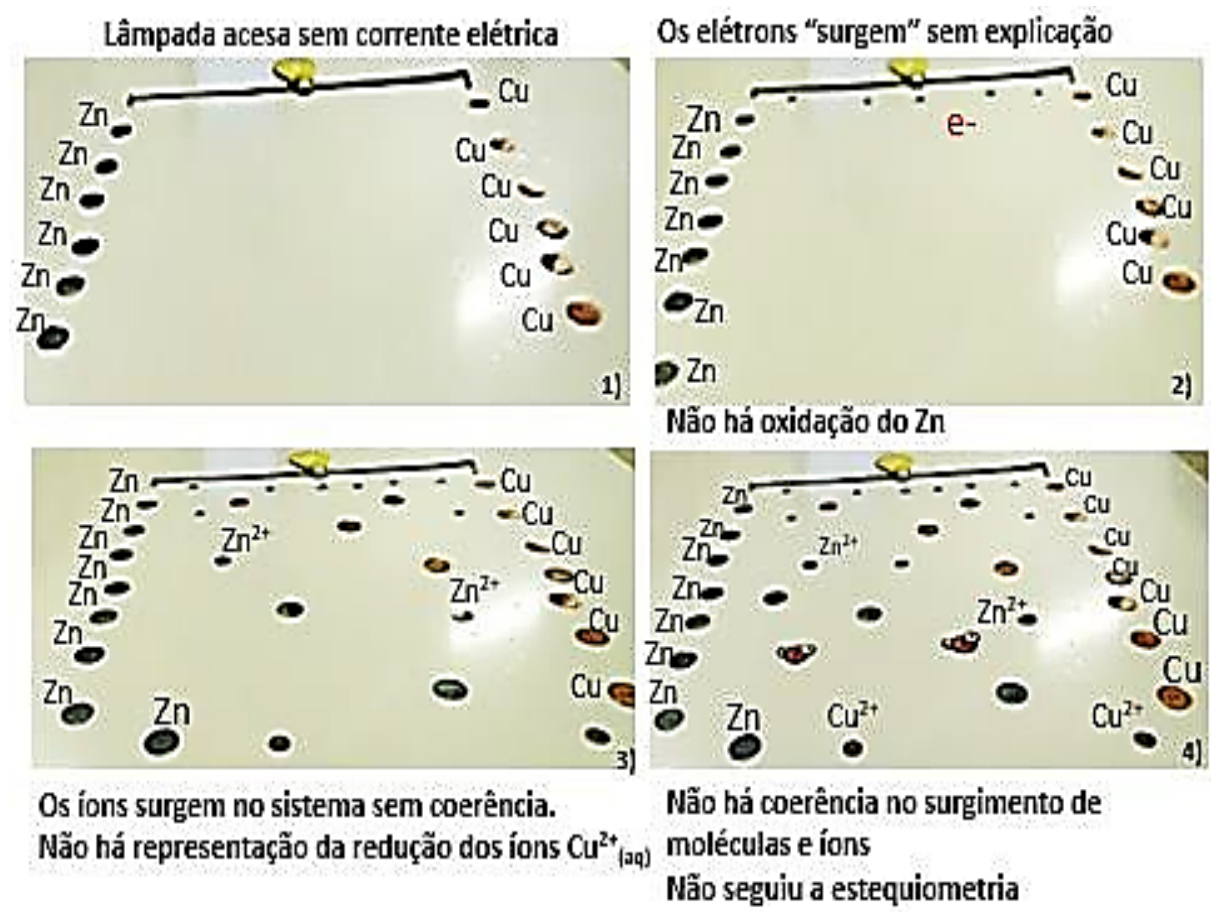

Fonte: Elaborado pelos autores.

Como expresso na figura acima, o grupo 2 não representou a oxidação dos átomos de zinco, e, portanto, o surgimento dos elétrons foi incoerente, assim como, mesmo na ausência de corrente elétrica (fluxo de elétrons) a lâmpada estava acesa. Na ausência de reações de oxidação, os elétrons não são gerados. Consequentemente, a corrente elétrica seria inexistente, e a pilha permaneceria apagada.

Também não houve representação da redução dos íons $\mathrm{Cu}_{(\mathrm{aq})}{ }^{2+}$, embora o número de átomos de cobre tenha aumentado no cátodo, representando o ganho de massa. O grupo não representou qualquer forma de estequiometria nas reações. 0 desconhecimento da estequiometria demonstra que os alunos, neste ponto, ainda não compreenderam a proporção com que os íons, átomos ou moléculas reagem, devido aos modelos mentais incoerentes ou imprecisos. 


\section{CONSIDERAÇÕES FINAIS}

Foi observado grande avanço na construção dos modelos mentais, já que anteriormente, pelo Questionário inicial, até mesmo o fluxo retilíneo de elétrons, era um conceito desconhecido para os alunos. E o método de ensino empregado se mostrou vantajoso, através do qual os alunos conseguiram atuar como protagonistas, passando a ter maior senso crítico, pelo ato de "manipular" a matéria no nível submicroscópico através de animações representativas de átomos, íons, moléculas e elétrons.

Os alunos participaram efetivamente da atividade de geração de animações, o que sugere que a utilização de recursos tecnológicos e associados aos materiais imagéticos, trouxeram benefícios em termos de curiosidade, retenção da atenção, e estímulo ao raciocínio lógico. Estes fatores colaboram efetivamente para o desenvolvimento cognitivo e geração de modelos mentais mais adequados a respeito do sistema químico estudado.

As animações permitiram identificar as principais dificuldades dos alunos, seja relacionada à troca iônica e reações de oxidação e redução, movimentação das espécies químicas ou entendimento da estequiometria de uma reação. Também cabe citar que os erros cometidos pelos grupos foram reconhecidos por eles mesmos quando a animação feita pela pesquisadora foi exibida aos alunos, o que levou a uma discussão e retirada de dúvidas. Nesse momento, percebeu-se que os estudantes compreenderam efetivamente o sistema por meio da visualização da animação, e os aspectos que anteriormente eram abstratos e incompreensíveis passaram a ser entendidos de uma melhor forma.

E como os modelos mentais são altamente dinâmicos, e tendem a se modificar com o tempo, tanto pelo aprimoramento, quanto pelo esquecimento e regressão, é totalmente importante que o professor conheça os pontos falhos no modelo mental dos estudantes, para que eventualmente atue na correção de tais imperfeições. Isso corriqueiramente pode ser feito em sala de aula, pela utilização de atividades semelhantes, pelo estímulo ao diálogo, e por intermédio das discussões que poder ser geradas frente às frequentes dúvidas que os alunos possam ter.

\section{REFERÊNCIAS}

BUESO, Antoni; FURIÓ, Carles; MANS, Claudi. Interpretación de las reacciones de oxidación reducción por los estudiantes. Primeros resultados. Enseñanza de las ciencias, v.6, n.3, p.244-250, 1988.

CARAMEL, Neusa; PACCA, Jesuína. Concepções Alternativas em Eletroquímica e Circulação da Corrente Elétrica. Caderno Brasileiro Ensino de Física, v.28, n.1, p.726, 2011. 
FLICK, Uwe. Introdução à pesquisa qualitativa. 3. ed. Porto Alegre: Artmed e Bookman, 2009.

FREIRE, Melquesedeque da Silva; SILVA JÚNIOR, Carlos Neco; SILVA, Marcia Gorette Lima. Dificuldades de aprendizagem no ensino de eletroquímica segundo licenciandos de química. 2012. Disponível em: http://www.nutes.ufrj.br/abrapec/ viiienpec/resumos/R1150-1.pdf.Acesso em: 30 jan. 2019.

GIBIN, Gustavo Bizarria. Investigação sobre a construção de modelos mentais para o conceito de soluções por meio de animações. 138f. Dissertação (Mestrado em Química) - Centro de Ciências Exatas e de Tecnologia, Universidade Federal de São Carlos, São Carlos. 2009.

GÜNTHER, Hartmut. Pesquisa Qualitativa Versus Pesquisa Quantitativa: Esta é a Questão? Universidade de Brasília. Psicologia: teoria e pesquisa, v.22, n.2, p.201210, 2006.

JOHNSON-LAIRD, Philip. Mental models: towards a cognitive Science of language, inference, and consciousness. Cambridge, MA: Harvard University Press, 1983.

JOHNSTONE, Alex. The development of chemistry teaching. University Chemistry Education, v.70, n.9, p.701-705, 1993.

MOREIRA, Marco Antonio; GRECA, Ileana María; PALMERO, Maria Luz Rodriguez. Modelos mentales y modelos conceptuales en la enseñanza \& aprendizaje de las ciencias. Revista Brasileira de Investigação em Educação em Ciências, v.2, n.3, p.37-57, 2002.

NORMAN, Donald. Some observations on mental models. In: GENTNER, Deder; STEVENS, Albert (eds.). Mental models. Hillsdale, NJ: Lawrence Erlbaum Associates, 1983.

ROCHA, et al. Pilha de Daniell: Concepções Apresentadas por alunos do $2^{\circ}$ ano do Ensino Médio de uma Escola Pública de Ituiutaba - MG. 2017. Disponível em:

https://www.editorarealize.com.br/revistas/conedu/trabalhos/TRABALHO_EV073_ MD1_S A16_ID7291_11092017143758.pdf. Acesso em: 29 jan. 2019.

RUSSEL, et al. Use of simultaneous-synchronized macroscopic, microscopic, and symbolic representations to enhance the teaching and learning of chemical concepts. Journal of Chemical Education, v.74, n.3, p.330-334, 1997. 
SILVA, et al. A Experimentação e o relatório científico na construção do conhecimento para alunos do ensino fundamental. 2011. Disponível em: http:// www.nutes.ufrj.br/abrapec/viiienpec/resumos/R1232-1.pdf. Acesso em: 29 jan. 2019.

SILVA, Sonjenaria Guedes. As Principais Dificuldades na Aprendizagem de Química na Visão dos Alunos do Ensino Médio. 2013. Disponível em:http://portal. ifrn.edu.br/pesquisa/editora/livros-para-download/anais-do-ix-congic-ifrn. Acesso em: 27 jan. 2019

\section{BIOGRAFIA DOS AUTORES}

ANGÉLICA MATTIOLLI RODRIGUES - Licencianda em Química pela Universidade Estadual Paulista "Júlio de Mesquita Filho" Campus Presidente Prudente. Fez iniciação científica na área de Ensino de Química, nos seguintes temas: experimentação, abordagem investigativa, processos de ensino e aprendizagem e investigação de modelos mentais de estudantes.

GUSTAVO BIZARRIA GIBIN - Licenciado em Química pela Universidade Federal de São Carlos (2006), mestre em Química pelo Programa de Pós Graduação em QuímicaUFSCar (2009) e doutor em Ciências também pelo Programa de Pós Graduação em Química-UFSCar (2013). Tem experiência na área de Educação Química e atua principalmente nos seguintes temas: experimentação e abordagem experimental investigativa; análise e produção de materiais didáticos, livros didáticos, imagens, processos de ensino e aprendizagem, além de investigações sobre modelos mentais. Atualmente é professor assistente doutor da UNESP Universidade Estadual Paulista, Campus Presidente Prudente (http://www.fct.unesp.br/). É credenciado no Programa de Pós-Graduação em Ensino e Processos Formativos (http://www.ibilce.unesp. br/\#!/pos-graduacao/programas-de-pos-graduacao/ensino-e-processos-formativos/ apresentacao/).

Data de recebimento: 01/09/2020

Data de aprovação: 23/10/2020 